\title{
Research on Collaborative Problem-Solving Supported by Multi-screen and Multi-touch Teaching System
}

\author{
Zhaoli Zhang, Yang Li, and Hai Liu
}

\begin{abstract}
The ability of work collaboratively is highly valued to improve students' cognition in today's workplace, especially in the area of education which was supported by information and communication technologies. Learning environment of classroom must strive to support the development of collaborative problem-solving activities. In this paper, we present a constructivist problem solving activity based on the multi-screen and multi-touch teaching system for fostering the development of cognition in classroom, based on which we conducted a $2 \times 2$ experimental design in the dimensions of learning environment and learner's prior knowledge to explore effects on students' primary and advanced cognition. Findings from the experience provide an indication that the main effect of prior knowledge factor on the primary cognition and the main effect of learning environment factor on the advanced cognition were significant. In addition, a qualitative evaluation to capture students' thoughts and feelings about participating in the problem solving activities was conducted, results show that the ability of information expression especially to present work to other group members still should be improved.
\end{abstract}

Index Terms-Collaborative problem solving, multi-screen and multi-touch teaching system, primary cognition, advanced cognition.

\section{INTRODUCTION}

Collaborative problem solving (CPS) is considered as one of the core competencies of the 21 st century [1]. The significance of improving students' CPS is clear to most educators and CPS has become part of many common constructivist teaching approaches including problem-based learning, inquiry-based learning, project-based learning, and practice-based learning. For some decades, it was common to see that learners work with group members to solve a problem during these teaching approaches, and there have been strong advocates of these teaching approaches in Education, arguing their merits in achieving such high-tier learning objectives [2], [3]. It is believed that the social interactions during a problem solving activity are helpful in developing students' zone of proximal development, as the interaction is situated in a

Manuscript received March 2, 2018; revised August 14, 2018. This research was partially supported by the National Natural Science Foundation of China under Grant (No. 61505064), Hong Kong Scholars Programs under Grant (No. XJ2016063), the National Natural Science Foundation of Hubei Province under Grant (No. 2016CFB497), the National key Research and Development Program (No. 2017YFB1401301, 2017YFB1401303), the Cultivating Excellent Doctoral Dissertations Program of CCNU (No. 2017YBZZ009), and the Specific Funding for Education Science Research by Self-determined Research Funds of CCNU (No. CCNU16JYKX031).

The authors are with the School of National Engineering Research Center for e-Learning, Central China Normal University, Wuhan, Hubei, 430079 China (e-mail: zl.zhang@mail.ccnu.edu.cn, 1y0104@mails.ccnu.edu.cn, hailiu0204@gmail.com). meaningful context [4], [5], perhaps that is why these constructivist teaching approaches are considered to help foster the 21st-century skills that young people require.

CPS activities supported by information and communication technologies (ICTs) may promote the development of collective intelligence and distributed cognition by complementary ways [6]-[8], as students construct shared meaning interacting with tools that may facilitate and scaffold the collaboration process [9]. In response to the need of classroom learning tools' capabilities for fostering the teaching of 21 st century skills, the design and application of multi-screen display technology and multi-touch technology has become a new trend of information-based teaching and research. The combination of both can create collaborative, synchronous, competitive, interactive physics classroom environment. The screen, as an important part of the classroom environment, is not only an important carrier of teaching and learning information, but also the main medium connecting physical space and information space.

In this paper, we present a collaborative problem solving activity that leverages multi-screen and multi-point touchable teaching system called Starc which is self-developed by our team as a means to support co-construction and sharing of knowledge in problem-solving scenarios. This study explored the impact of both learning environment and learners' priori knowledge levels on the understanding of primary and advanced cognition through collaborative problem solving activity. A survey was also conducted to investigate students' feeling about the collaborative problem solving.

\section{CONCEPTUAL FRAMEWORK}

\section{A. About Collaborative Problem-Solving}

Collaborative problem solving is designed for people who work together face-to-face or in online workspace as equals to solve a real word problem. These group members can share a common concern, a similar passion, and a commitment to their works. CPS involves a set of sophisticated interaction skills that need to be utilized at the same time in service of supporting, directing, facilitating and coordinating the thinking of others with one's own, to achieve a mutually agreed goal. Compared with individual-based simulations, students' actions in a collaborative simulation will simultaneously influence the shared problem state, and can thus support a dual interaction space. Furthermore, the simulation can also regulate asymmetric accountability in a CPS activity since only when all the members closely coordinate to manipulate the simulation can they solve the 
problem.

\section{B. Technologies for Social Collaborative Learning}

With the rapid development of ICT (information and communication technologies), however, technologies play an increasingly important role in collaboration. The complexity of tasks in the knowledge economy society requires people to work together as it is hard for individuals to possess all knowledge and skills. Collaboration becomes a necessary skill in the present society. Meanwhile, technologies have become an integrated part of our lives. People are using various technological devices such as computers and mobile phones to communicate and interact with others. Undoubtedly the use of technologies has made communication and collaboration more convenient and affordable than before. Nevertheless, technologies are not a necessary condition or a panacea for effective collaboration. It is not the mere presence or complexity of technologies that improves learning experiences, but the quality of match between technologies and the learning task [10].

The use of technologies in collaborative learning has the potential to benefit students and teachers. Students can use ICT as a communication tool, a productivity tool, a repository, or a documentation tool [11]. Teachers can use ICT to monitor and track the collaborative learning process, so that they can fairly assess students' individual contributions and identify problems promptly [12], [13].

\section{INSTRUCTIONAL DESIGN AND IMPLEMENT}

Based on the environment supports mentioned in Chapter 3, we designed the collaborative problem solving activity which is shown in diagram Fig. 1. We used a Unified Modelling Language (UML) activity diagram to illustrate pedagogical flow. UML (2011) is a standard modelling language for software products and process specifications and instructional activity can be described as a control flow in a collaborative activity. The pedagogical flow can be divided into 3 stages: the first stage of student analysis, the second stage of collaborative problem solving and the third stage of evaluation.

In the first stage, before an activity is initiated in the classroom, the teacher generate a collection of students' prior knowledge by making students conduct a test through the use of Starc teaching system's intelligent statistical function, based on which students are divided into groups heterogeneously. Then, teacher can design and assign the task to every body's Pad. This is the most basic and crucial stage which decides the degree of completion.

In the second stage, the activity is initiated in the classroom once all of the students have received the available tasks by using the Pad. The students must solve the presented task individually by using Pad to search for information, solely relying on their previous knowledge and current level of competence. Then, they would collaborate with other group members ("Collaborative Problem Solving" in Fig. 1), carrying related resource that they searched just now. Groups can apply Pad and the screen around classroom through the direct touch screen operation. At this stage, the teacher may offer limited support only intended to clarify students' questions regarding the task definition itself ("Monitor Activity" in Fig. 2). If the groups finish their solutions, they can submit them to the teacher electronically through Pad. The teacher then reviews the students' solutions using the teacher side screen and selects a subset that involves different strategies, novel idea, etc. Thus can improve competitiveness between different groups and push them to finish well. Next, groups whose solution was selected would present and explain their solutions ("Show Solution" in Fig. 2) by using the side screen and all of the screen in classroom can show the same content to make everyone see clearly. At this time, other groups including those who hasn't finished and who has finished but hasn't shown their solutions should listen to the presenters in order to initiate a discussion.

The third stage is designed mainly to evaluate and improve. When the groups whose solutions have been shown, they comment on their work first, then the other group and teacher will evaluate it and give some suggestions, based on which, all the groups will modify and improve their solutions. Now, each group can use the groups that have shown their solutions for reference, especially those groups whose solutions haven't finished yet.

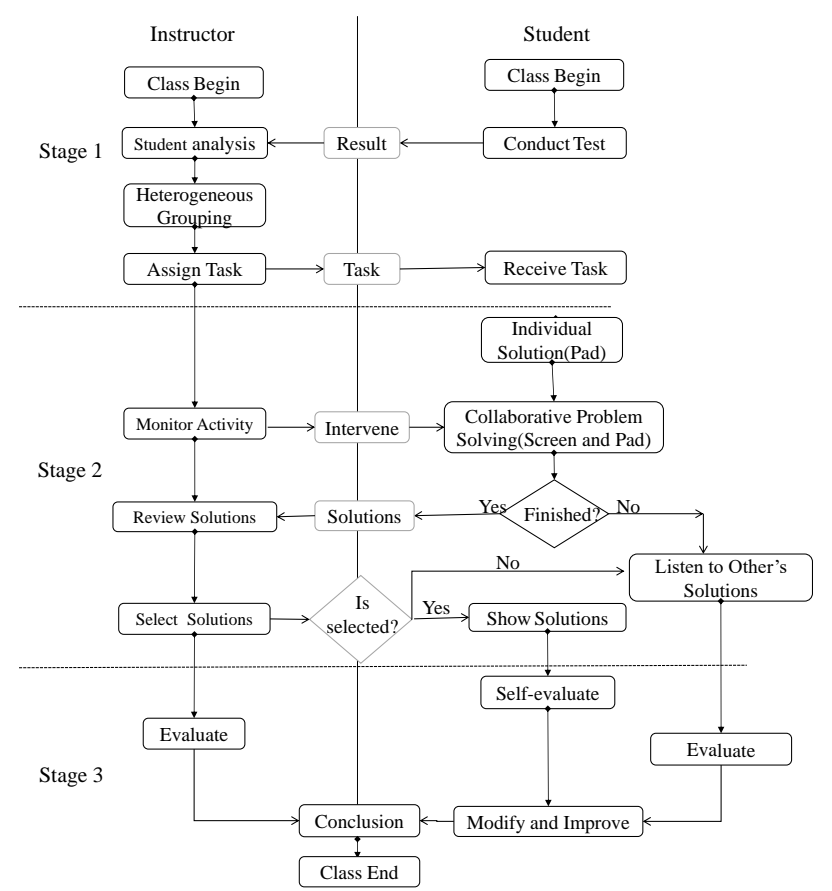

Fig. 1. Pedagogical flow of collaborative problem solving activity.

A detailed flow of the collaborative problem solving process about groups is depicted in Fig. 3. Discussion begin when every member of one group have had some ideas after searching for information. In the process of collaborative problem solving, members of a group should identify problem which will be solved first and then conduct problem presentation. Everyone should explain his or her solutions, and the leader of each group integrate the program of each member ("Negotiation and Reconstruction" in Fig.2.), which is also a process of thoughts communication and collision. Through the members' negotiation, each group can determine a solution and use mind mapping, PowerPoint or other tools to visualize the scheme. It is necessary to make feasibility evaluation, based on which to modify the solution and review every link. 


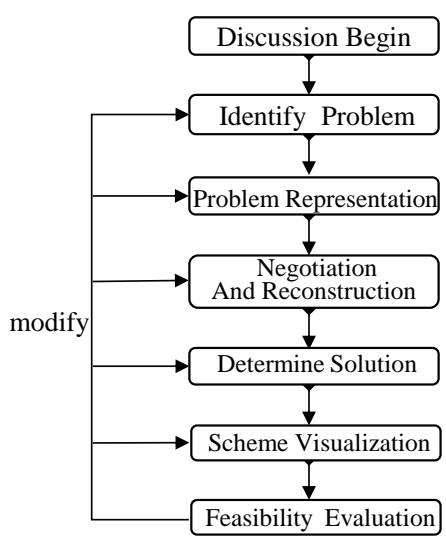

Fig. 2. Special flow of collaborative problem solving activity.

\section{PRACTICE AND DISCUSSION}

\section{A. Task Design and Sample}

The design of this research is based on the collaborative problem solving activities that mentioned in chapter 3 and takes the classroom environment which has been constructed into account. The task was mainly to construct three-level evaluation index system about the quality of MOOCs. In this study, we select 73 students (32 graduate students and 41 undergraduates) that major in the educational technology of Central China Normal University. These learners already acquired the knowledge relating to the course of "pedagogy" "psychology" "teaching design". And every student have learned one lesson called "Teach You How to Make MOOC" on the MOOC of Chinese University platform, the lesson was published by Peking University. Therefore, the students are familiar with MOOCs.

\section{B. Learning Environment}

Collaborative problem solving activities was carried out in the smart classroom that has been built with multi-screen multi-touch teaching system called Starc of Central China Normal University. Starc teaching system which is based on PGP electronic dual-board teaching platform is independently developed by Engineering Center. The structure as figure 3 shows. The teaching system is mainly composed of five parts: education cloud platform, teacher side, student side, screens around classroom and internet. The teacher side is composed of four 85-inch LCD TV panels and can support single-screen, double-screen as well as multi-screen display which depend on external split-screen graphics and software technology. The Starc teaching system's specific application environment called smart classroom which is constructed with the concept of "cloud-terminal integration". In the other words, the smart classroom integrates the teaching desktops, learning desktops, teacher aides, student assistants, interaction between teachers and students, different terminal devices in the system with resources, applications as well as services in the cloud platform to form a cloud-terminal integration learning environment, in which learners can conduct independent learning, collaborative research, group discussions and other personalized learning styles through multiple-point touchable LCD screens around classroom and personal learning terminals such as Pad or phones. In addition, they can realize direct control to touch screen, electronic blackboard writing, audio and video broadcast, simulation experiments, three-dimensional simulation of animation playback, screen annotation and other teaching functions.

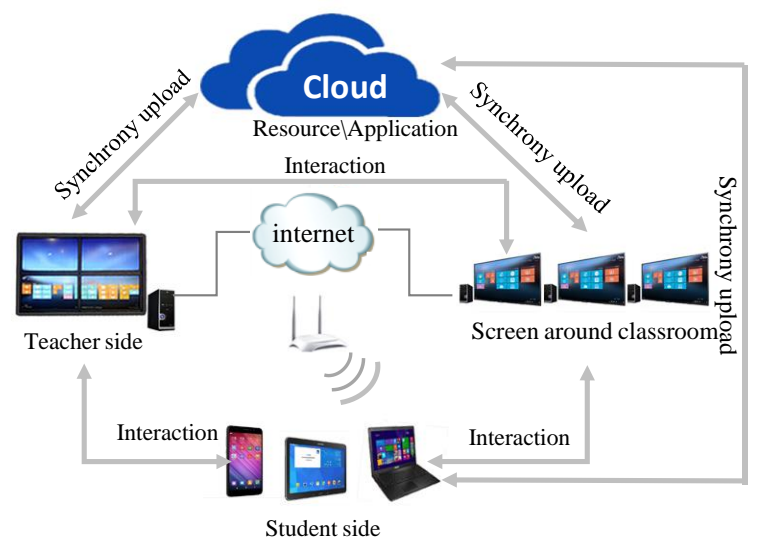

Fig. 3. Structure of Starc teaching system.

\section{Methodology}

This study conducted a $2 \times 2$ experimental design in the dimensions of learning environment (traditional learning environment and smart classroom learning environment) and learner's prior knowledge (high prior knowledge and low prior knowledge). In the element of prior knowledge, 32 graduate students represent learners with high prior knowledge and 41 undergraduates represent learners with low prior knowledge. 16 graduate students and 20 undergraduates were assigned to a traditional learning environment and other students were assigned to a smart classroom learning environment, each group consisting of four to five members at random.

Based on Schraw and Dennison's Knowledge and Cognition Framework [14], this study developed a pre-test and post-test questionnaire to assess learners' knowledge of domain knowledge. First, according to the characteristics of declarative knowledge, 10 judgment questions and 10 single choice questions are designed around the topic of "MOOC Making", which mainly to examine learners' memory understanding of related knowledge and can be used to evaluate learner's primary cognitive state of understanding. Second, according to the characteristics of conditional and step-by-step knowledge, we designed one interpretation questions, one essay question and one innovation design title about MOOC curriculum around the topic of "MOOC Quality Evaluation", which mainly examine learners' overall and associative understanding of learning topics and can be used to assess learners' advanced cognitive state of understanding.

In the end of the class, a survey was conducted in the classroom and the students were asked to complete a paper-based. The aim of the survey was to gain students' perception and feelings of collaborative problem solving as well as capture their attitudes about participating in the activities. The survey contained 12 questions from five dimensions including learning attitude, information management, information expression, group collaboration and environment support, which were Likert-based questions on a five-level scale (i.e., level 1 associated with "strongly disagree" and level 5 associated with "strongly agree"), 
especially the last two question were only filled by students in smart classroom.

\section{Result Analysis}

1) Impact of prior knowledge and learning environment on primary cognition development

In order to explore the influence of prior knowledge and learning environment on learner's primary cognitive development, this part uses two-factor covariate analysis of independent samples to analyze the effects of learning intervention on learners' primary cognitive development in four cases. The result is shown in table 1, exclude the impact of pre-test scores, the main effect of learning environment factor did not reach the significant level, $\mathrm{F}=4.27, \mathrm{P}=0.069$ > 0.05 . However, the main effect of prior knowledge factor at the primary cognition reached a significant level, $\mathrm{F}=7.59, \mathrm{P}$ $=0.027<0.05$.

TABLE I : RESULTS OF EFFECTS ON PRIMARY COGNITIVE COMPREHENSION

\begin{tabular}{|l|c|c|c|c|c|c|}
\hline Source & $\begin{array}{c}\text { Type } \\
\text { III SS }\end{array}$ & df & $\begin{array}{c}\text { Mean } \\
\text { Square }\end{array}$ & F & Sig & $\begin{array}{c}\text { Eta } \\
\text { Square }\end{array}$ \\
\hline Pre-test & 60.24 & 1 & 60.24 & 18.73 & 0.000 & 0.305 \\
\hline $\begin{array}{l}\text { Priori } \\
\text { Knowledge }\end{array}$ & 13.21 & 1 & 13.21 & 7.59 & 0.027 & 0.071 \\
\hline $\begin{array}{l}\text { Learning } \\
\text { Environment }\end{array}$ & 7.56 & 1 & 7.56 & 4.27 & 0.069 & 0.037 \\
\hline Deviation & 196.67 & 69 & 3.052 & & & \\
\hline
\end{tabular}

\section{2) Impact of prior knowledge and learning environment} on advanced cognition development

In contrast to the above analysis, this part's dependent variable is the advanced cognitive comprehension data, mainly reflected by the score of understanding question in the test paper. The result is shown in Table II, exclude the impacts of pre-test scores, the main effect of prior knowledge factor did not reach the significant level, $F=1.73, P=0.189>0.05$. However, the main effect of learning environment factor at the primary cognitive reached a significant level, $F=14.50, P$ $=0.003<0.05$.

TABLE II : Results OF EFFECTS ON PRIMARY COGNITIVE

\begin{tabular}{|l|c|c|c|c|c|c|}
\hline Source & $\begin{array}{c}\text { Type } \\
\text { III SS }\end{array}$ & df & $\begin{array}{c}\text { Mean } \\
\text { Square }\end{array}$ & F & Sig & $\begin{array}{c}\text { Eta } \\
\text { Square }\end{array}$ \\
\hline Pre-test & 10.46 & 1 & 10.46 & $\begin{array}{c}15.8 \\
3\end{array}$ & 0.000 & 0.135 \\
\hline $\begin{array}{l}\text { Priori } \\
\text { Knowledge }\end{array}$ & 3.39 & 1 & 3.39 & 1.73 & 0.189 & 0.161 \\
\hline $\begin{array}{l}\text { Learning } \\
\text { Environment }\end{array}$ & 7.56 & 1 & 7.56 & $\begin{array}{c}14.5 \\
0\end{array}$ & 0.003 & 0.024 \\
\hline Deviation & 56.91 & 69 & 0.153 & & & \\
\hline
\end{tabular}

\section{3) Analysis of the statistical results of the survey}

Table III shows the results of the survey. With regard to students' learning attitude (question 1-2), the results $(M>3)$ of the survey were consistent with our observations in the classroom. The students in general were more motivated to participate and take an active role in the group. In the aspect of information processing (question 3-4), students could generally search, organize and share information around a topic. According to the results of question 5-6, the ability of information expression should be improved, especially to present group work to other group members. As with the group collaborative aspects (question 7-10), students' satisfactions were not too high because the environment including desks or chairs and other equipment can't provide sufficient convenience for students in the traditional classroom to conduct demonstration and communication. The dimension of environment support (question 11-12) was filled by students who learnt in smart classroom, the results $(M>4)$ demonstrate that design of smart classroom is conducive to students collaborative learning.

TABLE III: STATISTICAL RESUlT OF THE SURVEY

\begin{tabular}{|c|c|c|c|}
\hline Dimension & Question & M & SD \\
\hline \multirow{2}{*}{$\begin{array}{l}\text { Learning } \\
\text { Attitude }\end{array}$} & 1. I could trust others and speak freely in & 3.27 & 1.25 \\
\hline & 2. I could share information with others & 4.03 & 0.71 \\
\hline \multirow{2}{*}{$\begin{array}{l}\text { Information } \\
\text { Processing }\end{array}$} & 3. I could accurately find, analyze and & 4.33 & 0.52 \\
\hline & 4. I could processing information & 3.76 & 1.23 \\
\hline \multirow{2}{*}{$\begin{array}{l}\text { Information } \\
\text { Expression }\end{array}$} & 5. I could talk to my classmates more often & 3.34 & 1.37 \\
\hline & 6. I volunteered to present our group & 2.31 & 2.01 \\
\hline \multirow{4}{*}{$\begin{array}{c}\text { Group } \\
\text { Collaboration }\end{array}$} & 7. I feel that collaborative problem solving & 3.52 & 0.54 \\
\hline & 8. I feel that the group has a reasonable & 3.24 & 0.62 \\
\hline & 9. I feel that in the process of problem & 3.20 & 0.91 \\
\hline & 10. I feel that according to the actual & 3.06 & 1.97 \\
\hline \multirow{2}{*}{$\begin{array}{c}\text { Environment } \\
\text { Support }\end{array}$} & 11. I feel the touch screen is necessary for & 4.02 & 0.34 \\
\hline & 12. System functions can help group & 4.11 & 0.29 \\
\hline
\end{tabular}

\section{CONCLUSION}

Combine with the multi-screen and multi-touch teaching system, this paper present a constructivist problem solving activity for fostering the development of cognition in classroom. Results from the experience indicate that prior knowledge has significant effect on the primary cognition and learning environment with multi-screen and multi-touch teaching system can improve the advanced cognition. In addition, no matter students in traditional classroom or smart classroom, they were satisfied with the collaborative problem solving activity. However, compared with students studying in smart classroom, satisfaction of students learning in traditional classroom was lower on the aspect of group collaboration. It is noteworthy that the ability of information expression especially to present work to the whole class members still should be improved.

\section{REFERENCES}

[1] P. Griffin et al., Assessment and Teaching of 21st Century Skills: Methods and Approach, New York, NY: Springer, 2012.

[2] B. Barron and L. Darling-Hammond, "Prospects and challenges for inquiry-based approaches to learning," The Nature of Learning: Using Research to Inspire Practice, p. 199e225, 2010.

[3] M. Montessori, Spontaneous Activity in Education, London: Benediction Classics, 1965.

[4] J. Lave and E. Wenger, Situated Learning: Legitimate Peripheral Participation, Cambridge, UK: Cambridge University Press, 1991.

[5] L. S. Vygotsky, Mind in Society: The Development of Higher Psychological Processes, Cambridge, MA: Harvard University Press, 1978. 
[6] P. Dillenbourg and P. Jermann, "Designing integrative scripts," Scripting Computer-Supported Collaborative Learning, Springer, May 31, 2011.

[7] L. M. Fawcett and A. F. Garton, "The effect of peer collaboration on children's problem-solving ability," The British Journal of Educational Psychology, vol. 75(Pt2), p. 157169, 2015.

[8] A. Weinberger, K. Stegmann, and F. Fischer, "Knowledge convergence in collaborative learning: concepts and assessment," Learning and Instruction, vol. 17, no. 4, pp. 416-426, 2007.

[9] P. Dillenbourg, S. Jarvela, and F. Fischer, The Evolution of Research on Computer-Supported Collaborative Learning, Springer, 2007.

[10] P. Jermann, A. Soller, and A. Lesgold, "Computer software support for CSCL," What We Know About CSCL, pp. 141-166, Norwell, MA: Kluwer Academic Publishers, 2004.

[11] V. Kaptelinin, "Learning together: Educational benefits and prospects for computer support," The Journal of the Learning Sciences, vol. 8 , no. $3 \& 4$, pp. $499-508,1999$.

[12] C. Chan and J. Aalst, "Learning, assessment and collaboration in computer-supported environments," What We Know about CSCL, pp. 87-112, Norwell, MA: Kluwer Academic Publishers, 2004.

[13] F. Pozzi et al., "A general framework for tracking and analysing learning processes in computer-supported collaborative learning environments," Innovations in Education and Teaching International, vol. 44, no. 2, pp. 169-179, 2007.

[14] G. Schraw and R. S. Dennison, "Assessing metacognitive awareness," Contemporary educational psychology, 1994, vol. 19, no. 4, pp. 460-475.

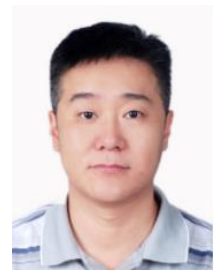

Zhaoli Zhang received a bachelor's degree in physics from Peking University in 1995, a master's degree in computer science from Huazhong Normal University in Wuhan in 2004. From 2004 to 2008, he enrolled in school of computing of Huazhong University of Science and Technology and received a doctorate. From 2008 to 2010, a postdoctoral degree was received in Education Information Technology Engineering Research Center.
From 2010, he is a professor, and working at the National Engineering Research Center for E-Learning, Wuhan, Hubei, China. His research interests include software engineering, computer application technology, cloud computing and big data.

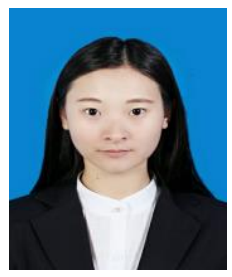

Yang $\mathbf{~} \mathbf{i}$ is a master student studying at the National Engineering Research Center for E-Learning, Wuhan, Hubei, China. Her research interests include educational technology and learning behavior analytics.

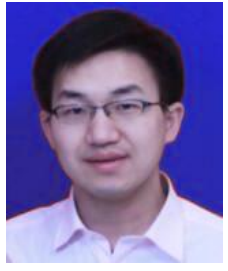

Hai Liu obtained a master's degree in Applied Mathematics from the School of Mathematics and Statistics at Huazhong University of Science and Technology in 2010. In 2014, he received Ph.D in Huazhong University of Science and Technology Institute of Image Recognition and Artificial Intelligence Control Science and Engineering. From June 2014 till now, he is a lecturer, and working at the National Engineering Research Center for e-Learning, Wuhan, Hubei, China. His research interests include blended learning, facial expression recognition and learning behavior analytics. 